\title{
Lateralization of vigilance in geese: influence of flock size and distance to the source of disturbance
}

\section{Elmira Zaynagutdinova, Karina Karenina, and Andrey Giljov}

Department of Vertebrate Zoology, Faculty of Biology, Saint Petersburg State University, Universitetskaya nab., 7-9, Saint Petersburg, 199034, Russian Federation

Address correspondence and requests for materials to Elmira Zaynagutdinova, e.zainagutdinova@spbu.ru

\begin{abstract}
Left-eye preference, implicating right hemisphere advantage, is typical for vigilant behaviour of many vertebrates. Nevertheless, lateralization of vigilance may be manifested in other ways, such as different reactions to the danger viewed with the right and left eye. Here, we studied one-side biases in the orientation of whitefronted geese Anser albifrons feeding in flocks at different distances to the source of anthropogenic disturbance (a road with traffic) and in flocks of different sizes. The birds which used the left eye to monitor the road were at shorter distances to the road than the birds which used the right eye. The tendency to monitor the road with the right eye decreased with increasing flock size. Trade-offs between feeding, social and vigilant behaviour could explain these tendencies.
\end{abstract}

Keywords: vigilant behaviour, antipredator behaviour, social behavior, sensory lateralization, visual lateralization, white-fronted goose, disturbance, hunting, flight initiation distance, lateral bias.

\section{Introduction}

The dominance of one brain hemisphere in the implementation of any function can be manifested in animal behaviour in the form of one-sided preferences, for example, preference to inspect a stimulus with one eye. For the last several decades, the manifestation of asymmetric brain functioning in sensory perception of various stimuli - sensory lateralization - has been found in a diverse range of animal behaviours (Rogers et al., 2013). The contribution of lateralization to biological fitness is one of the key questions in this field (Rogers, 2000; Frasnelli and Vallortigara, 2018). Many studies, therefore, have focused on lateralized behaviours associated with detection of predators or other threats, which is a fundamental mechanism of individual survival. Antipredator behaviour has been studied in a wide variety of species ranging from invertebrates to fish, mammals, and birds (De Santi et al., 2001; Rogers, 2002; Schnell et al., 2016; Romano et al., 2017). The right brain hemisphere and the left eye have been found to be responsible for vigilant behaviour in many species (Rogers and Kaplan, 2005; Martín et al., 2010; Austin and Rogers, 2012; Bonati et al., 2013). However, some studies on animals in the wild failed to confirm the consistent use of the left eye to monitor predators (Franklin and Lima, 2001; Randler, 2005; Beauchamp, 2013). It was hypothesized that consistent one-sided behavioural bias would make prey species predictable for predators; therefore, the presence of predators in nature has to be monitored by both the left and right sensory organs (Blumstein et al., 2018). Nevertheless, sensory lateralization in antipredator behaviour can occur in other ways, for example, in the lateral biases in flight initiation distance, latency of the escape response, and intensity of alarm calls (Nottebohm, 1972; Rogers and Kaplan, 2005; Blumstein et al. 2018). In this case, sensory lateralization at different distances to the threat also could be the subject of the study. 
In the majority of previous studies, lateralization of antipredator behaviour was assessed using animals tested or observed individually (Lippolis et al., 2005; Randler, 2005; Austin and Rogers, 2012). However, in a social setting, predator evasion requires social coordination and a uniform pattern of movement. In a shoal, flock, or herd, the consistent movement of conspecifics is necessary to increase the efficiency of predator avoidance, e.g., it helps to avoid collision of groupmates when moving away from the predator (Robins et al., 2018). Sensory lateralization is known to be manifested in the coordinated behaviour of individuals in a group, e.g., in cetaceans (reviewed in MacNeilage, 2013). That is, an aggregation of individuals can also be the object of study of lateralized behaviour. For example, lateralized group behaviour has been investigated in domestic reindeer (Rangifer tarandus) (Espmark and Kinderev, 2002). Vigilant behaviour of the group of animals and the effect of the group size on it could be studied in birds with social behaviour, for example, on geese.

Predator avoidance is essential for survival and affects population size (Begon et al., 1996). As anthropogenic disturbance affects the birds' behaviour and food accessibility near the source of disturbance, it can also affect population size (Bellebaum and Kruckenberg, 2009). Research on this issue may be necessary for the management of populations of threatened species or species that are subject to significant human impact such as hunting pressure (Boutin, 1992; Madsen et al., 1999; Zöckler et al., 2010). In this regard, the white-fronted goose (Anser albifrons) was chosen as the subject of our study. It is one of the essential hunting goose species in Europe (Fox and Leafloor, 2018). In most countries, goose hunting is allowed only during autumn migration or in winter, but spring hunting is allowed in Russia. During migration stopovers, geese must replenish energy reserves to continue migration. Many goose species also use energy reserves from migration stops for breeding in the Arctic (Jefferies and Drent, 2006). Hunting during spring migration affects the population not only through additional mortality but also indirectly by changing the behaviour of the birds (Kruckenberg et al., 2008). Disturbance during migration stops reduces feeding intensity as birds spend more time on alert (Riddington et al., 1996). Deterioration of feeding conditions during migration affects the reproductive success of individuals, which may lead to population decline (Mainguy et al., 2002; Feret et al., 2005). Disturbance can have an impact on the distance at which birds stay away from the danger. Exclusion zones may appear around the source of the disturbance. Even if feeding conditions are favourable in these areas, birds are unable to take advantage of them (Kruckenberg et al., 2008; Bellebaum and Kruckenberg, 2009).
Our study thus focused on the behaviour of whitefronted geese during the spring migration stopover. Visual lateralization in flocks at different distances to the source of anthropogenic disturbance and in flocks of different sizes was investigated.

\section{Methods}

\section{Subjects and data collection}

Observations of geese behaviour were made at one of the well-known spring migration stopovers near the village Aleksala, Olonets Region, Karelia, Russia. Tens of thousands of geese stay on the fields for several weeks in April and May during their spring migration to the breeding grounds in the Russian Arctic (Zimin et al., 2007). At this time, birds intensively feed on fodder crops, replenishing energy reserves to continue migration. In Russia, spring hunting is open during the geese migration, and birds are faced with intense hunting pressure in this period. To save the migration stopover, a protected area (Game Resting Area) was organized in the region, but the area of this reserve is small (5000 ha) and hunting is allowed in the surroundings (Zimin et al., 2007). The protected area is crossed by an intercity road with medium traffic intensity. During the stopover birds always keep a distance from roads, which seem to be their main disturbing factor.

Three species of geese stay in the area during migration in huge numbers. These are the white-fronted goose (Anser albifrons), bean goose (A.fabalis) and barnacle goose (Branta leucopsis). Birds stay in single-species or mixed flocks. Our study focused on the behaviour of the white-fronted goose because this species is the most numerous during the hunting season and the peak of migration (Zimin et al., 2007). For data collection, the flocks where white-fronted geese dominated (the proportion of white-fronted geese was more than twothirds of the total number of birds) were used.

Birds on the field may feed, rest, sleep, or be on alert (Zimin et al., 2007). The data were scored on the flocks with feeding birds only. Feeding behaviour was found to be the most common type of behaviour during migration stopover. Flocks feeding on the fields were observed 28 April-12 May 2019 during the peak of migration and the hunting season at the Game Resting Area.

The observations and photography were conducted from the country road crossing the fields. The observer approached the nearest point to the flock. Behaviour observations and distance measurements were only made if the observer's approach to the nearest point on the road did not change the behaviour of the geese. If birds were alert, stopped feeding or left the feeding place, no measurements were made. The distance from the closest bird to the road was measured by the size in pixels 


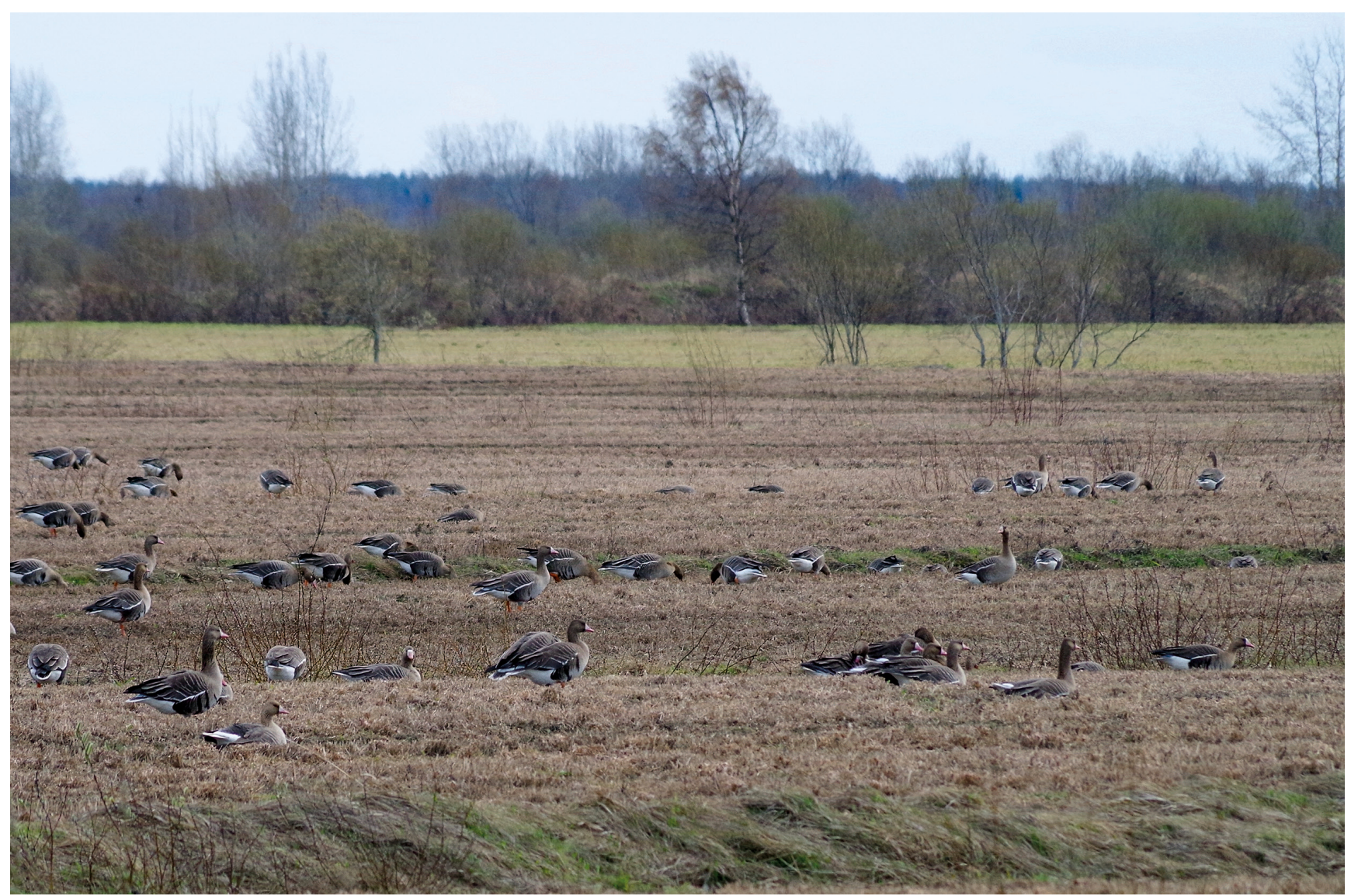

Fig. 1. White-fronted geese feeding in the field.

of the closest bird in the photo. The photo was taken from the road from the closest position to the flock. The real size from the breast to the tail was measured on the stuffed white-fronted goose from the collection of the Department of Vertebrate Zoology, St. Petersburg State University, and was equal to $0.48 \mathrm{~m}$. The distance to the bird was calculated by triangle similarity and according to the following formula:

$$
\begin{aligned}
& \mathrm{d}=\left(0.3^{\star}(0.48+\mathrm{H})\right) / \mathrm{H} \\
& \mathrm{H}=\mathrm{n}^{\star} 0.01 / 2079
\end{aligned}
$$

where $\mathrm{n}-$ number of pixels in the photo; $0.3 \mathrm{~m}-$ focal length of the lens; 2079 pixels/cm - camera matrix size; $0.48 \mathrm{~m}$ - linear goose size

The observer photographed the whole flock and made sure not to take photos of the same birds. The number of birds oriented with their left and right side, tail, and chest towards the road was calculated on the photos. The flock was classified as Left if two conditions were met simultaneously:

a) The number of the birds oriented with their left eye to the road was twice (or more) as big as the number of the birds oriented with their right eye to the road;

b) The left-sided position was observed in more than $50 \%$ of all birds, including the birds oriented with their left and right side, tail, and chest towards the road.
Thus, the flock was classified as Left if both:

Left / Right $>2$ and Left > Right + Tail + Chest.

In a similar way, the Right flocks were classified if:

Right / Left > 2 and Right $>$ Left + Tail + Chest .

The remaining flocks were categorized as Different.

The approximate number of birds in the flock was also calculated to analyze the influence of the flock size on the group one-sided bias. The observer counted the number of birds in the flock watching the birds through binoculars from the road.

Since wind direction could influence the position of the birds because they prefer to start flight against the wind (Videler, 2005), wind direction relative to the birds' position was defined for every flock observation.

An average of 16,000 white-fronted geese were observed daily in the study area, which corresponds with typical numbers for this stopover (Zimin et al., 2007). The size and composition of the flocks varied considerably. Some birds joined the flocks, while some birds left the flocks. Moreover, during the day, birds moved to different fields. Given these factors, each observation was carried out for a single flock with a unique composition of individuals. During the day, the single flock was observed only at one observation point. The fields similar in size, 


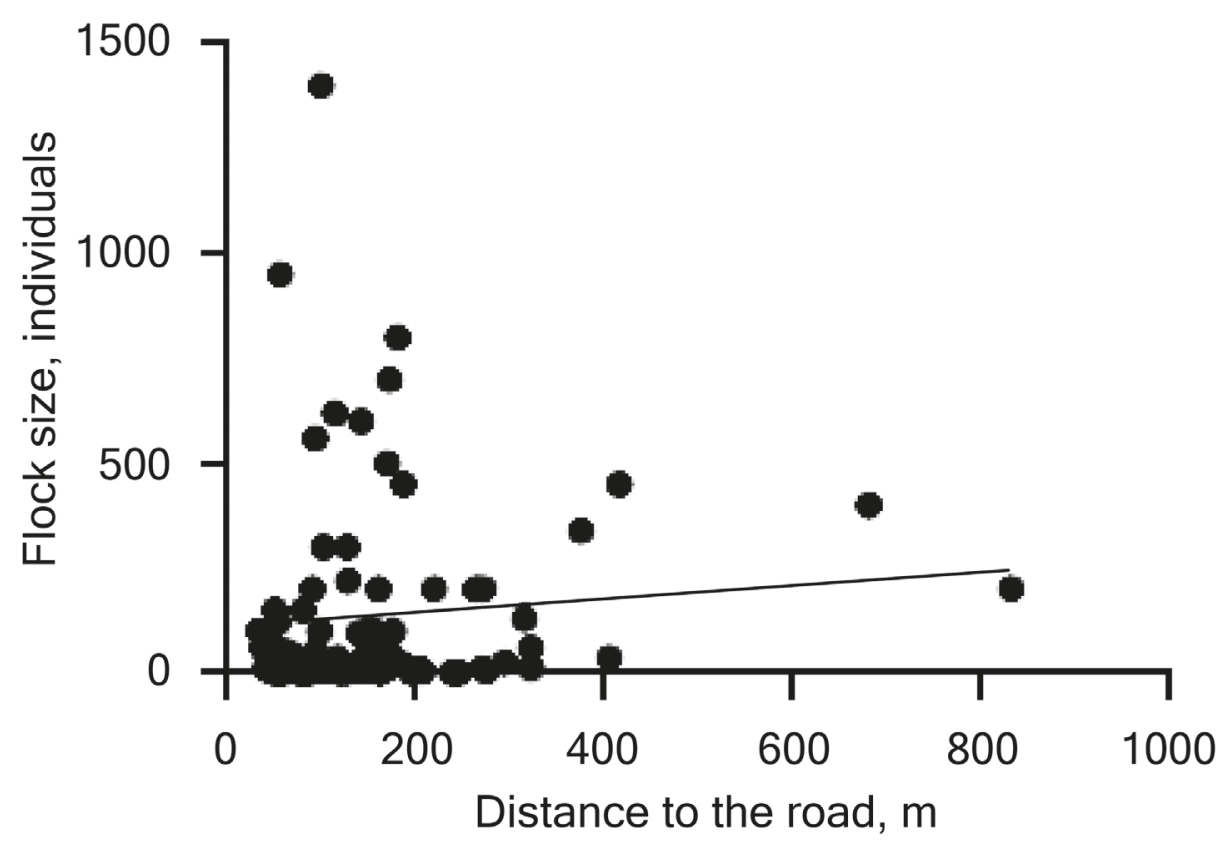

Fig. 2. Linear regression analysis with the distances from the flocks to the road $(m)$ and flock sizes (individuals).

location and orientation to the road were selected for the observations. In total, 88 feeding flocks with the dominance of white-fronted geese were observed (Fig. 1).

\section{Statistical analysis}

The $X^{2}$ observed vs expected test was used to analyze wind directions and the direction of eye use across the group. Linear regression analysis was used to determine an association between the distance to the road and the size of the flock. The differences of the distances from the road and the flock sizes for the flocks oriented with left, right eyes or in different directions to the road were analyzed with the Mann-Whitney U test, Kruskal-Wallis test, and Dunn's post hoc tests. The influence of the distance to the road as well as flock size on one-eye use was also analyzed using the logistic regression model. For this test, flocks were assigned into four categories (1-10, 11-50, 51-100 and 100+ birds). The analyses were conducted using STATISTICA 7 and the JASP Statistical Analysis (ver. 0.9.0.1; https://jasp-stats.org/). All tests were two-tailed, and the significance level was set at $\mathrm{p}<0.05$.

\section{Results}

The distances from the flocks to the road varied from 32 to $830 \mathrm{~m}$, median [95\%CI] 139m [115 to 162], and the flock size varied from 2 to 1400 birds, median 32 [20 to 60]. Linear regression analysis failed to reveal a significant association between the distance to the road and the size of the flock $\left(R^{2}=0.00687\right.$, ANOVA: $F(1.86)=0.596, p=0.442)($ Fig. 2$)$
In the majority of flocks (69 out of 88), most individuals exhibited the same direction of eye use across the group $\left(X^{2}=28.41, d f=1, p<0.001\right)$. Birds in 41 flocks were oriented with their left eyes to the road, and birds in 28 flocks were oriented with their right eyes to the road. In 19 flocks, birds had different orientations to the road. This distribution differs significantly from those expected by chance (L $25 \%$, R $25 \%, \mathrm{~N} 50 \% ; X^{2}=32.25$, $d f=2, p<0.001)$. However, there was no significant bias to monitor the road with the left or right eye $\left(X^{2}=2.50\right.$, $d f=1, p=0.113$ ).

The distance to the road had a significant influence on the orientation of geese in the flock (Left, Right and Different) (Kruskal-Wallis test: $H=9.06, p=0.011$, $N=88$ ). Dunn's post hoc tests showed that the flocks which used the right eye to observe the road and the flocks with birds oriented in different directions were at greater distances to the road than the flocks which used the left eye $(p<0.05)$. No difference was found between the flocks with birds oriented in different directions and the flocks which used the right eye (Dunn's test: $p>0.05$ ). The median distance [95\%CI] for the flocks with the birds observing the road with the left eye was $115 \mathrm{~m}$ [86 to 143]; right eye-149 m [114 to 238]; and for the flocks with birds oriented differently $-175 \mathrm{~m}$ [98 to 270] (Fig. 3, Supplementary Data Set ${ }^{1}$.

The number of birds did not significantly differ in flocks with birds oriented with their left eyes to the road,

${ }^{1}$ Supplemental material to the article is available at https://biocomm.spbu.ru/article/view/6840 


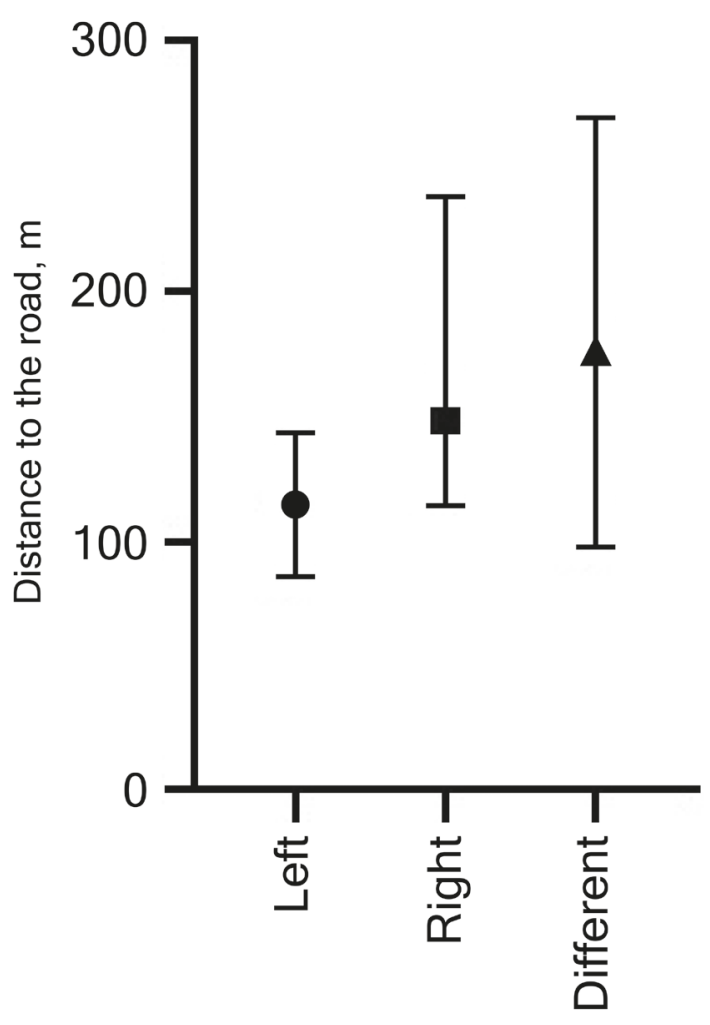

Orientation of birds

Fig. 3. Distances to the road (median, $95 \% \mathrm{Cl}$, m) for the flocks with left, right or different orientation of the birds to the road.

in flocks with birds oriented with their right eyes to the road, and flocks with birds having different orientations to the road (Kruskal-Wallis test: $H=3.55, p=0.170$, $N=88$ ) (Fig. 4). The median [95\%CI] flock size for the flocks with the birds observing the road with the left eye was 50 individuals [20 to 120 ]; right eye -15 individuals [6 to 60]; and for the flocks with birds oriented differently -25 individuals [ 15 to 200 ].

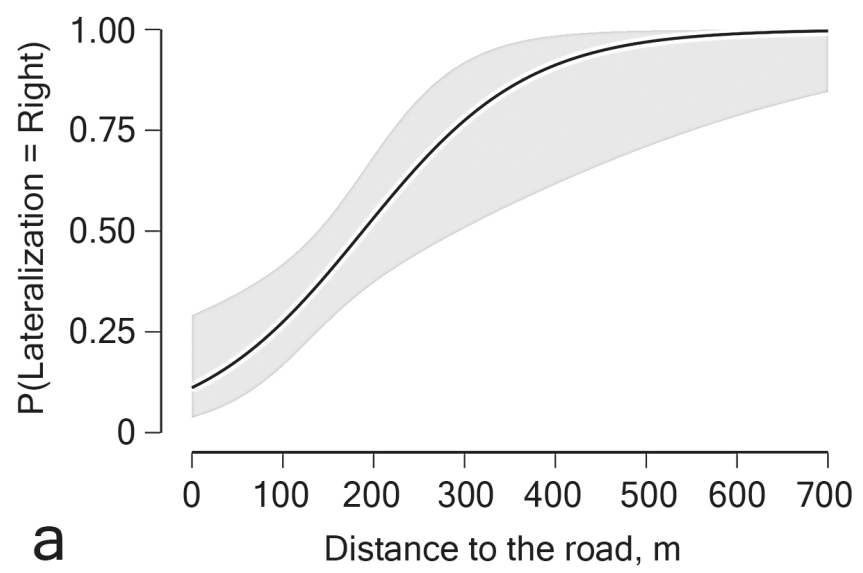

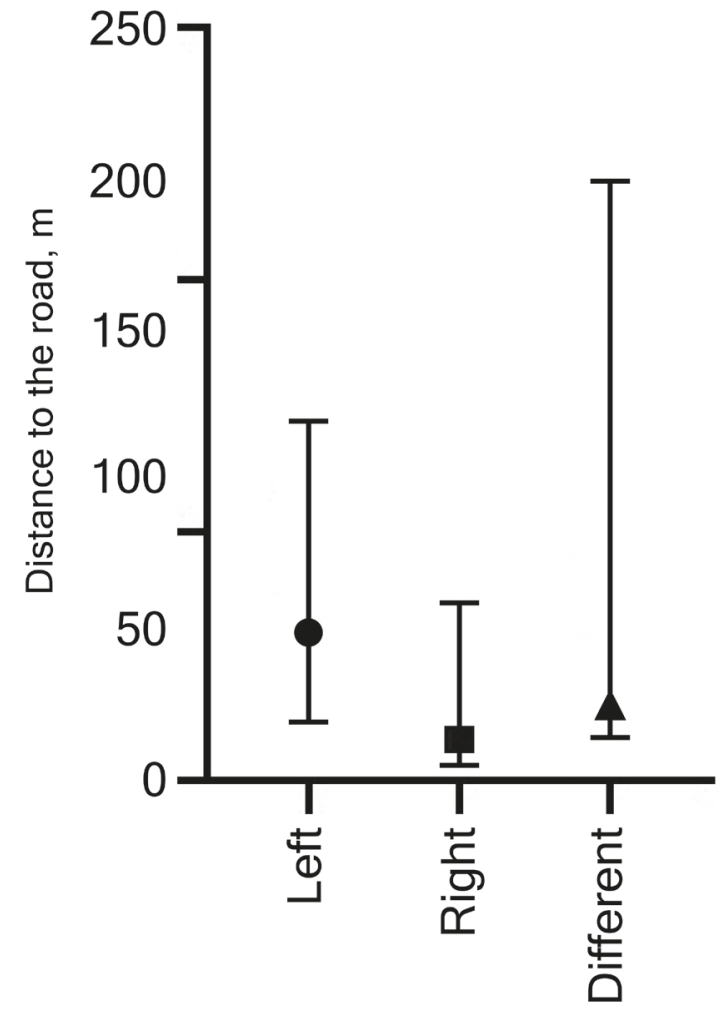

Orientation of birds

Fig. 4. Flock sizes (median, $95 \% \mathrm{Cl}$, individuals) for the flocks with left, right or different orientation of the birds to the road.

We further used logistic regression to examine the contribution of the distance to the road and flock size variables to the birds' Left/Right orientation in flocks. The full model was significant $\left(X^{2}=15.52, p<0.001\right)$. The flocks of geese which were at greater distances to the road tended to use the right eye $(p<0.05$; Fig. $5 a)$, and the tendency to monitor the road with the right eye decreased with increasing flock size ( $p<0.05$; Fig. $5 b)$.

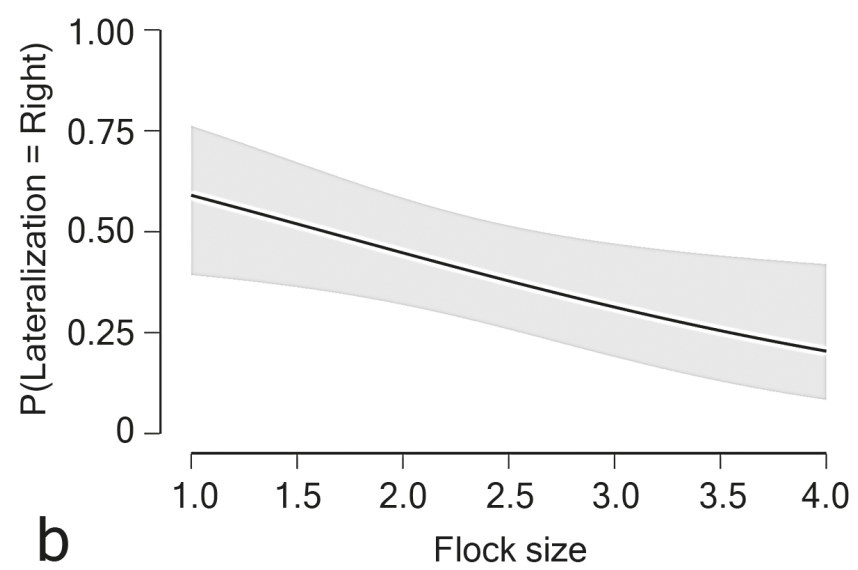

Fig. 5. Logistic regression model with eye use as dependent variable and distance to the road (a) and flock size (b) as covariates. Probability of right-eye use is coded as class 1, left is coded as class 0; the grey shadow indicates $95 \% \mathrm{Cl}$. The distance was calculated in meters from the observer to the nearest bird in the flock. Flocks of different size were divided into four categories (see Methods). 


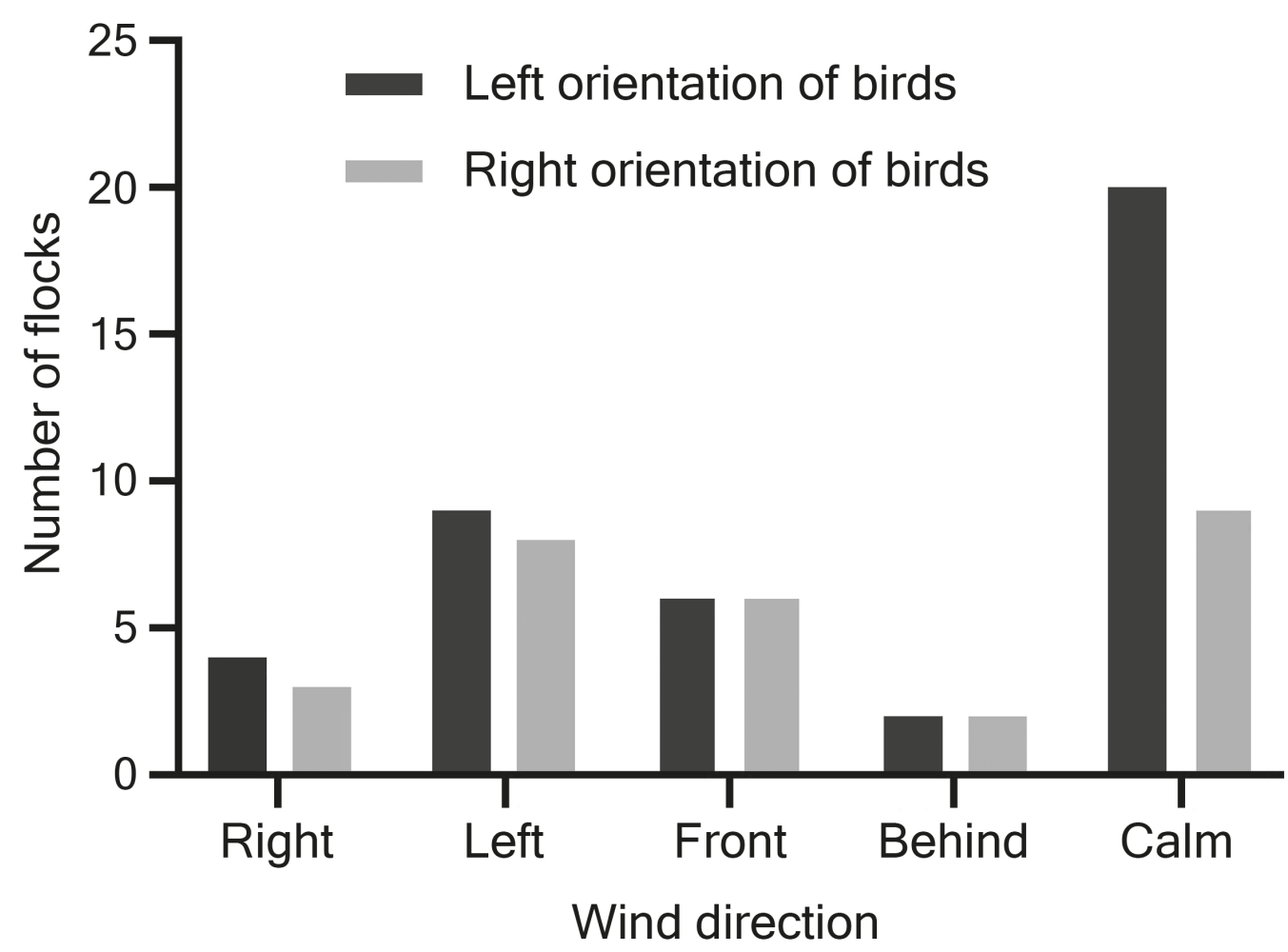

Fig. 6. Number of flocks with the birds oriented to the road with their left or right eyes in different wind conditions.

As birds prefer to start flight against the wind, we analyzed the association between wind direction and birds' position, distance to the road, and flock size. In calm weather, 20 flocks were oriented with their left eyes to the road, 9 flocks were oriented with their right eyes to the road, and 6 flocks had different orientation. For windy weather, we analyzed the orientation of the flocks to the road according to the wind direction. As wind direction was fixed according to the flock, we analyzed only the flocks where the majority of the birds had the same position. In windy weather, there was no significant bias to monitor the road with the left or right eye $\left(X^{2}=0.46, d f=3, p<0.93\right)$ (Fig. 6). With rightward wind direction, four flocks were oriented to the road with their left eyes; three were oriented to the road with their right eyes. With leftward wind direction, nine flocks were oriented to the road with their left eyes; eight were oriented to the road with their right eyes. With frontward wind direction, six flocks were oriented to the road with their left eyes, and six were oriented to the road with their right eyes. With tailward wind direction, two flocks were oriented to the road with their left eyes, and two were oriented to the road with their right eyes.

To see whether wind direction affects eye use, five groups with different wind direction were analyzed as separate groups (Table 1,2). Almost as in all groups, the same tendencies as for the total sample were observed, but the differences were not significant as the sample sizes were too small.

\section{Discussion}

Observations of solitary individuals are necessary to study lateralization at the individual or population level. Such studies are quite numerous (Rogers et al., 2013). However, the impact of the group on animal orientation is quite strong, because population lateralization may have been developed in relation to the need to maintain coordination among individuals in behaviours associated with social life (Rogers, 1989; Bisazza et al., 2000). In our study, individuals in most flocks were oriented in one direction, and only in some flocks, the distribution of birds was random. The design of our study allows us to conclude lateralization bias at the level of social groups. At the same time, we cannot interpret our results at the individual or population level.

Left-eye preference has been found in the vigilance behaviour of many animal species (Rogers and Kaplan, 2005; Martín et al., 2010; Schnell et al., 2016). However, in our study in white-fronted geese, one-side bias for monitoring a source of disturbance was not revealed. There may be several reasons for that.

While our results are not in line with a common pattern, they are not exceptional. Lateralization of vigilance can differ even between closely related species, as shown, for example, in the three species of emberizid sparrows (Franklin and Lima, 2001). In some species, vigilance behaviour evokes a right-eye bias (Franklin and Lima, 2001; Chivers et al., 2016; Romano et al., 2017) or no 
Table 1. Distance to the road $(\mathrm{m})$ for the flocks with the birds observing the road with the left, right eye and for the flocks with birds oriented differently with right, left, front and tail wind direction to the birds and in calm weather

\begin{tabular}{|c|c|c|c|c|c|}
\hline \multirow{2}{*}{$\begin{array}{l}\text { Wind direction to } \\
\text { the birds }\end{array}$} & \multicolumn{5}{|c|}{ The orientation of the birds to the road } \\
\hline & & Left & Right & Different & \\
\hline \multirow{4}{*}{ Calm } & Median & 133 & 171 & 197 & \multirow{4}{*}{$\begin{array}{l}\text { Kruskal-Wallis test: } \\
\mathrm{H}=4.82, \mathrm{p}=0.09, \mathrm{~N}=35\end{array}$} \\
\hline & Min & 40 & 73 & 37 & \\
\hline & Max & 294 & 416 & 405 & \\
\hline & $\mathrm{N}$ & 20 & 9 & 6 & \\
\hline \multirow{4}{*}{ Left wind } & Median & 53 & 193 & & \multirow{4}{*}{$\begin{array}{l}\text { Mann-Whitney } U \text { test: } \\
U=10, p<0.05, N=17\end{array}$} \\
\hline & Min & 33 & 49 & & \\
\hline & Max & 173 & 681 & & \\
\hline & $\mathrm{N}$ & 9 & 8 & & \\
\hline \multirow{4}{*}{ Right wind } & Median & 124 & 114 & & \multirow{4}{*}{$\begin{array}{l}\text { Mann-Whitney } U \text { test: } \\
U=4, p=0.48, N=7\end{array}$} \\
\hline & Min & 77 & 87 & & \\
\hline & Max & 196 & 315 & & \\
\hline & $\mathrm{N}$ & 4 & 3 & & \\
\hline \multirow{4}{*}{ Front wind } & Median & 127 & 134 & 98 & \multirow{4}{*}{$\begin{array}{l}\text { Kruskal-Wallis test: } \\
\mathrm{H}=0.03, \mathrm{p}=0.87, \mathrm{~N}=15\end{array}$} \\
\hline & Min & 93 & 50 & 56 & \\
\hline & Max & 219 & 322 & 181 & \\
\hline & $\mathrm{N}$ & 6 & 6 & 3 & \\
\hline \multirow{4}{*}{ Tail wind } & Median & 96 & 99 & & \multirow{4}{*}{$\begin{array}{l}\text { Mann-Whitney } U \text { test: } \\
U=2, p=1, N=2\end{array}$} \\
\hline & Min & 90 & 80 & & \\
\hline & Max & 102 & 117 & & \\
\hline & $\mathrm{N}$ & 2 & 2 & & \\
\hline
\end{tabular}

bias at all (Franklin and Lima, 2001; Beauchamp, 2013; Blumstein et al., 2018).

There may be some other explanations of the absence of lateral bias in geese vigilance. Social interactions could be very intensive in birds feeding in flocks. Many aspects of social behaviour are known to be predominantly controlled by the right hemisphere (left eye) (Rogers and Kaplan, 2005). A trade-off between social and vigilant behaviour in flocks can presumably hinder left eye bias for monitoring the source of disturbance. For example, the bias towards left-eye use for monitoring conspecifics may balance the left-eye bias for vigilance in birds in feeding flocks. The absence of the significant bias in our study may be a result of the mixture of two lateralized functions in the observed behaviour of geese, rather than a true absence of lateralization.

Another behavioural trade-off may also affect lateralization of vigilance. The right hemisphere is also known to control novelty detection (noticing small differences between stimuli) (Rogers and Kaplan, 2005), and it helps animals to feed efficiently. Guy Beauchamp
(2013) found that semipalmated sandpipers (Calidris pusilla) observing the feeding ground with their left eye and facing the riskier side of the habitat with their right eye captured significantly more prey than other birds. If the competition for food is high or the search for food is complicated, and the level of danger is low, it is more beneficial for the animals to use the left eye for feeding. In species with a high feeding rate such as geese, feeding and vigilance trade-offs are rather complicated (Randler, 2005).

It is also hypothesized that individuals who are too predictable in their response to predators could have reduced survival success (Rogers, 2000). Based on this, a selection for somewhat unpredictable responses can be expected (Blumstein et al., 2018). The absence of left-eye preference in observing the threat could be an adaptive antipredator behaviour in this case, but left-eye bias in vigilant behaviour may be revealed in another way. The better detection and recognition of potential threats by the right hemisphere (Rogers, 2010) may explain why the geese which were closer to the road were more prone 
Table 2. Flock size (individuals) for the flocks with the birds observing the road with the left, right eye and for the flocks with birds oriented differently with the right, left, front and tail wind direction to the birds and in calm weather.

\begin{tabular}{|c|c|c|c|c|c|}
\hline \multirow{2}{*}{$\begin{array}{l}\text { Wind direction to } \\
\text { the birds }\end{array}$} & \multicolumn{5}{|c|}{ The orientation of the birds to the road } \\
\hline & & Left & Right & Different & \\
\hline \multirow{4}{*}{ Calm } & Median & 50 & 23 & 28 & \multirow{4}{*}{$\begin{array}{l}\text { Kruskal-Wallis test: } \\
\mathrm{H}=0.25, \mathrm{p}=0.62, \mathrm{~N}=35\end{array}$} \\
\hline & Min & 2 & 5 & 6 & \\
\hline & Max & 600 & 450 & 200 & \\
\hline & $\mathrm{N}$ & 20 & 9 & 6 & \\
\hline \multirow{4}{*}{ Left wind } & Median & 70 & 7 & & \multirow{4}{*}{$\begin{array}{l}\text { Mann-Whitney } U \text { test: } \\
U=18.5, p<0.09, N=17\end{array}$} \\
\hline & Min & 3 & 2 & & \\
\hline & Max & 1400 & 400 & & \\
\hline & $\mathrm{N}$ & 9 & 8 & & \\
\hline \multirow{4}{*}{ Right wind } & Median & 2 & 130 & & \multirow{4}{*}{$\begin{array}{l}\text { Mann-Whitney } U \text { test: } \\
U=2.5, p=0.22, N=7\end{array}$} \\
\hline & Min & 2 & 2 & & \\
\hline & Max & 7 & 620 & & \\
\hline & $\mathrm{N}$ & 4 & 3 & & \\
\hline \multirow{4}{*}{ Front wind } & Median & 250 & 33 & 800 & \multirow{4}{*}{$\begin{array}{l}\text { Kruskal-Wallis test: } \\
\mathrm{H}=3.12, \mathrm{p}=0.08, \mathrm{~N}=15\end{array}$} \\
\hline & Min & 3 & 2 & 8 & \\
\hline & Max & 500 & 150 & 950 & \\
\hline & $\mathrm{N}$ & 6 & 6 & 3 & \\
\hline \multirow{4}{*}{ Tail wind } & Median & 250 & 19 & & \multirow{4}{*}{$\begin{array}{l}\text { Mann-Whitney } U \text { test: } \\
U=2, p=1.12, N=4\end{array}$} \\
\hline & Min & 200 & 2 & & \\
\hline & Max & 300 & 36 & & \\
\hline & $\mathrm{N}$ & 2 & 2 & & \\
\hline
\end{tabular}

to use the left eye, implicating the right hemisphere. It is plausible that birds in close proximity to the danger should make more effort to protect themselves than birds far from the danger.

Most vertebrates seem to show a similar lateralization pattern for emotional processing, with right-hemisphere dominance for processing negatively connotated emotions, such as fear and aggression, and left-hemisphere dominance for processing positively connotated emotions (Leliveld et al., 2013). The responses elicited by stimuli on the animal's left side are more likely to be associated with fear than are responses to the same stimuli on the animal's right side (Rogers, 2017). In bird species, alert inspection associated with high levels of fear has also been shown to be controlled by the right hemisphere function (Koboroff et al., 2009). Roads and traffic significantly affect animals' mortality and behaviour (Legagneux and Ducatez, 2013). Birds in the vicinity of the road could be more vigilant and stressed, while further away from the road birds can feed more and be less vigilant. Thus, the enhanced stress and fear at closer dis- tances to the road may elicit in geese the enhanced use of the left eye for monitoring the source of the disturbance.

The relationship between lateralized behaviour and the distance to danger can be studied using the flight initiation distance (FID), the distance between a predator and its prey at which the prey initiates flight (Cooper and Blumstein, 2015). This is one of the standard methods of studying vigilant behaviour. The results of studies considering both FID and lateralization of vigilance are inconsistent. In experiments with the Balearic lizard (Podarcis lilfordi, Lacertidae), the side of the approach did not affect flight initiation distance (Cooper and Pérez-Mellado, 2011). In contrast, yellow-bellied marmots (Marmota flaviventer) that looked at the approaching person with their left eye had larger FIDs, implicating that risk assessment was influenced by the eye used to monitor the threat (Blumstein et al., 2018). When responding to the approach of an unfamiliar, masked human, cattle were more likely to remove themselves from the potential threat viewed within the left and not right visual field (Robins et al., 2018). Future studies may ex- 
amine the link between visual lateralization and flight response in goose flocks. However, ethical concerns regarding the disturbance of birds which are already under significant hunting pressure may limit research opportunities in our study area. In this case, the measurement of the distances to the threat was an alternative to the FID in our study.

Group size has been repeatedly shown to affect flight initiation distance in various species (Dill and Ydenberg, 1987; Braimoh et al., 2018). In our study, the size of the flock did not depend on the distance to the road. The Kruskal-Wallis test also did not reveal significant differences in flock sizes with birds oriented with their left or right eyes to the road. Nevertheless, the logistic regression confirmed that the size of the flock influenced the visual bias - the more birds were in the flock, the higher was the tendency to use the left eye for monitoring the road. The more consistent visual bias in larger groups may be a result of the interplay between behavioural lateralization and social pressures, widely discussed in recent theoretical and empirical studies (reviewed in Frasnelli and Vallortigara, 2018). It is hypothesized that synergistic (cooperative) interactions in social animals serve as a driving force for the establishment and maintenance of population-level lateralization (Ghirlanda et al., 2009). The increased need for cooperation in larger flocks may be associated with more consistent use of the left eye for monitoring the source of the disturbance.

Since birds prefer to start flight against the wind (Videler, 2005), the wind direction could impact the positional preferences of birds, especially when vigilant. However, in our study, the absence of lateral bias in geese vigilance was observed irrespective of the wind direction. We assume that the visual monitoring of the road was more influential for the birds' positional preferences than the wind direction.

In our study, white-fronted geese did not exhibit oneside bias for monitoring a threat, but lateralization of vigilance was manifested in other ways, such as the effect of the group size and distance to the threat on the one-side bias of vigilant behaviour. Reasons may include adaptive antipredator behaviour, enhanced stress and trade-offs between social, feeding and vigilant behaviour.

\section{Acknowledgements}

We are deeply grateful to Yegor Malashichev for his support, assistance and valuable discussions in the course of the study planning. We thank Denis Galkin and Elena Galkina for their helpful assistance in the fieldwork. We would like to thank Vadim lurkov for his help in the organization of the fieldwork.

\section{References}

Austin, N. P. and Rogers, L. J. 2012. Limb preferences and lateralization of aggression, reactivity and vigilance in feral horses, Equus caballus. Animal Behaviour 83(1):239-247. https://doi.org/10.1016/j.anbehav.2011.10.033
Beauchamp, G. 2013. Foraging success in a wild species of bird varies depending on which eye is used for antipredator vigilance. Laterality 18(2):194-202. https://doi. org/10.1080/1357650X.2011.648194

Begon, M., Mortimer, M., and Thomson, D. J. 1996. Population ecology: A unified study of plants and animals (3rd ed.). Oxford: Blackwell Sci.

Bellebaum, J. and Kruckenberg, H. 2009. Impact of hunting: from escape distance to the loss of feeding area. In Goose Specialist Group 12th Meeting. 9-13 October Hölviken. Sweden, p. 11.

Bisazza A., Cantalupo C., Capocchiano M., and Vallortigara G. 2000. Population lateralisation and social behaviour: A study with 16 species of fish. Laterality 5(3):269-284. https://doi.org/10.1080/713754381

Blumstein, D. T., Diaz, A., and Yin, L. 2018. Marmots do not consistently use their left eye to respond to an approaching threat but those that did fled sooner. Current Zoology 64(6):727-731. https://doi.org/10.1093/cz/zoy003

Bonati, B., Csermely, D., and Sovrano, V. A. 2013. Looking at a predator with the left or right eye: Asymmetry of response in lizards. Laterality 18(3):329-339. https://doi.or g/10.1080/1357650X.2012.673623

Boutin, S. 1992. Predation and moose population dynamics: A critique. The Journal of Wildlife Management 56(1):116127. https://doi.org/10.2307/3808799

Braimoh, B., Iwajomo, S., Wilson, M., Chaskda, A., Ajang, A., and Cresswell, W. 2018. Managing human disturbance: factors influencing flight-initiation distance of birds in a West African nature reserve. Ostrich 89(1):59-69. https:// doi.org/10.2989/00306525.2017.1388300

Chivers, D. P., McCormick, M. I., Allan, B. J. M., Mitchell, M. D., Goncëalves E.J., Bryshun R., and Ferrari, M. C. O. 2016. At odds with the group: changes in lateralization and escape performance reveal conformity and conflict in fish schools. Proceedings of the Royal Society B 283:20161127. https://doi.org/10.1098/rspb.2016.1127

Cooper, W.E. and Blumstein, D.T. 2015. Escaping from predators: An integrative view of escape decisions. Cambridge University Press. https://doi.org/10.1017/ CBO9781107447189

Cooper, W. E. and Pérez-Mellado, V. 2011. Escape by the Balearic Lizard (Podarcis lilfordi) is affected by elevation of an approaching predator, but not by some other potential predation risk factors. Acta Herpetologica 6(2):247-259.

De Santi, A., Sovrano, V. A., Bisazza, A., and Vallortigara, G. 2001. Mosquitofish display differential left- and righteye use during mirror image scrutiny and predator inspection responses. Animal Behaviour 61:305-310. https://doi.org/10.1006/anbe.2000.1566

Dill, L. M. and Ydenberg, R. C. 1987. The group size - flight distance relationship in water striders (Gerris remigis). Canadian Journal of Zoology 65(2):223-226. https://doi. org/10.1139/z87-036

Espmark, Y. and Kinderes, K. 2002. Behavioural lateralisation in reindeer. Rangifer 22:51-59. https://doi. org/10.7557/2.22.1.687

Feret, M., Bety, J., Gauthier, G., Giroux, J. F., and Picard, G. 2005. Are abdominal profiles useful to assess body condition of spring staging Greater snow geese? The Condor 107:694-702. https://doi.org/10.1093/condor/107.3.694

Fox, A. D. and Leafloor, J. O. (eds.) 2018. A global audit of the status and trends of Arctic and Northern Hemisphere goose populations. Conservation of Arctic Flora and Fauna International Secretariat, Akureyri, Iceland.

Franklin, W. E. and Lima, S. L. 2001. Laterality in avian vigilance: do sparrows have a favourite eye? Animal Behaviour 62:879-885. https://doi.org/doi:10.1006/anbe.2001.1826 
Frasnelli, E. and Vallortigara, G. 2018. Individual-level and population-level lateralization: two sides of the same coin. Symmetry 10(12):739. https://doi.org/10.3390/ sym10120739

Ghirlanda, S., Frasnelli, E., and Vallortigara, G. 2009. Intraspecific competition and coordination in the evolution of lateralization. Philosophical Transactions of the Royal Society B. Biological Sciences 364(1519):861-866. https:// doi.org/10.1098/rstb.2008.0227

Jefferies, R. L. and Drent, R. H. 2006. Arctic geese, migratory connectivity and agricultural change: calling the sorcerer's apprentice to order. Ardea 94(3):537-554.

Koboroff, A., Kaplan, G., and Rogers, L.J. 2008. Hemispheric specialization in Australian magpies (Gymnorhina tibicen) shown as eye preferences during response to a predator. Brain Research Bulletin 76(3):304-306. https://doi. org/10.1016/j.brainresbull.2008.02.015

Kruckenberg, H., Bellebaum, J., and Wille, V. 2008. Escape distances of staging Arctic geese along the flyway. Vogelwelt 129:169-173.

Legagneux, P. and Ducatez, S. 2013. European birds adjust their flight initiation distance to road speed limits. Biology Letters 9:20130417. https://doi.org/10.1098/ rsbl.2013.0417

Leliveld, L. M. C., Langbein, J., and Puppe, B. 2013. The emergence of emotional lateralization: Evidence in nonhuman vertebrates and implications for farm animals. Applied Animal Behaviour Science 145:1-14. https://doi. org/10.1016/j.applanim.2013.02.002

Lippolis, G., Westman, W., McAllan, B., and Rogers, L. 2005. Lateralisation of escape responses in the stripe-faced dunnart, Sminthopsis macroura (Dasyuridae: Marsupialia). Laterality: Asymmetries of Body, Brain, and Cognition 10(5):457-470. https://doi. org/10.1080/13576500442000210

MacNeilage, P. F. 2013. Vertebrate whole-body-action asymmetries and the evolution of right handedness: A comparison between humans and marine mammals. Developmental Psychobiology 55(6):577-587. https://doi. org/10.1002/dev.21114

Madsen, J., Cracknell, G., and Fox, A. D. (eds.) 1999. Goose populations of Western Paleartic. A review of status and distribution. Wetlands International Publ. No 48. Wetlands International, Wageningen, The Netherlands. National Environmental Research Institute, Rönde, Denmark.

Mainguy, J., Bĕty, J., Gauthier, G., and Giroux, J.-F. 2002. Are body condition and reproductive effort of laying greater snow geese affected by the spring hunt? The Condor 104:156-161. https://doi.org/10.1093/condor/104.1.156

Martín, J., López, P., Bonati, B., and Csermely, D. 2010. Lateralization when monitoring predators in the wild: A left eye control in the Common Wall Lizard (Podarcis muralis). Ethology 116(112):1226-1233. https://doi.org/10.1111/ j.1439-0310.2010.01836.x

Nottebohm, F. 1972. Neural lateralization of vocal control in a Passerine bird: II. Sub-song, calls, and a theory of vocal learning. Journal of Experimental Zoology 179:35-50. https://doi.org/10.1002/jez.1401790104
Randler, C. 2005. Eye preference for vigilance during feeding in coot Fulica atra, and geese Anser anser and Anser cygnoides. Laterality 10(6):535-543.

Riddington, R., Hassall, M., Lane, S. J., Turner, P. A., and Walters, R. 1996. The impact of disturbance on the behaviour and energy budgets of Brent Geese Branta b. bernicla. Bird Study 43(3):269-279. https://doi. org/10.1080/00063659609461019

Robins, A., Goma, A. A., Ouine, L., and Phillips, C.J.C. 2018. The eyes have it: lateralized coping strategies in cattle herds responding to human approach. Animal Cognition 21(5):685-702. https://doi.org/10.1007/s10071-0181203-1

Rogers, L. J. 1989. Laterality in animals. International Journal of Comparative Psychology 3:5-25.

Rogers, L.J. 2000. Evolution of hemispheric specialization: advantages and disadvantages. Brain and Language 73:236-253. https://doi.org/10.1006/brln.2000.2305

Rogers, L. J. 2002. Lateralization in vertebrates: Its early evolution, general pattern and development. Advances in the Study of Behavior 31:107-162. https://doi.org/10.1016/ S0065-3454(02)80007-9

Rogers, L.J. 2010. Relevance of brain and behavioural lateralization to animal welfare. Applied Animal Behaviour Science 127(1-2):1-11. https://doi.org/10.1016/j.applanim.2010.06.008

Rogers, L.J. 2017. Considering side biases in vigilance and fear. Animal Sentience 74:1-3.

Rogers, L. J. and Kaplan, G. 2005. An eye for a predator: Lateralization in birds with particular reference to the Australian Magpie. In Y. Malashichev and A. W. Deckel (eds.). Behavioural and Morphological Asymmetries in Vertebrates. Landes Boiscience. pp. 47-57.

Rogers, L.J., Vallortigara, G., and Andrew, R.J. 2013. Divided brains: The biology and behaviour of brain asymmetries. Cambridge University Press, Cambridge, UK. https://doi. org/10.1017/CBO9780511793899

Romano, D., Benelli, G., and Stefanini, C. 2017. Escape and surveillance asymmetries in locusts exposed to a Guinea fowl-mimicking robot predator. Scientific Reports 7:1-9. https://doi.org/10.1038/s41598-017-12941-z

Schnell, A. K., Hanlon, R. T., Benkada, A., and Jozet-Alves, C. 2016. Lateralization of eye use in cuttlefish: Opposite direction for anti-predatory and predatory behaviors. Frontiers in Physiology 7:620. https://doi.org/10.3389/ fphys.2016.00620

Videler, J.J. 2005. Avian flight. Oxford Ornithology Series. Oxford University Press, Oxford, UK. https://doi. org/10.1093/acprof:oso/9780199299928.001.0001

Zimin, V. B., Artemyev, A. V., Lapshin, N. V., and Tyulin, A. R. 2007. Olonets spring bird assemblages. Moscow, Science, 299 p. (In Russian)

Zöckler, C., Syroechkovskiy, E. E., and Atkinson, P. W. 2010. Rapid and continued population decline in the Spoonbilled Sandpiper Eurynorhynchus pygmeus indicates imminent extinction unless conservation action is taken. Bird Conservation International 20(2):95-111. https://doi. org/10.1017/S0959270910000316 